\title{
Public health implications of dietary differences between social status and occupational category groups
}

\author{
Alison M Smith, Katrine I Baghurst
}

\begin{abstract}
Study objective-As there is a social status gradient in chronic disease mortality in Australia, this study aimed to establish whether there were substantial differences among socioeconomically defined groups with respect to food choice and nutrient intake, in the context of risk of nutrition related chronic diseases.

Design and participants-Cross sectional data were collected from a randomly selected population sample of 1500 urban Australian adults. Data were collected by postal questionnaire, which included an assessment of dietary intake and questions on sociodemographic details. Three measures of social position were collected: occupation, educational status, and income status. Occupation was interpreted both on a continuous, prestige scale, and also as categorical occupational groupings.

Main results-The study achieved a $70 \%$ response rate. Higher social status was generally associated with healthier dietary intakes, with lower fat and refined sugar densities, and higher fibre densities, but also with higher alcohol density. No differences were found in salt, polyunsaturated fat, protein, or complex carbohydrate densities across groups. Food intake differences were also found between occupational status groups, with the upper social groups tend- ing to consume more wholegrain cereal foods, low fat milk, and fruit, and less refined cereal foods, full cream milk, fried meat, meat products, and discretionary sugar; but also more cheese and meat dishes.
\end{abstract}

Conclusions-Although this study did show statistically significant differences across social status groups in relation to nutrient and food intakes, these differences were small compared to the disparity between intakes of all groups and the recommended patterns of intake, and did not appear to be great enough to be a major explanatory variable in differences in disease risk across groups.

f Epidemiol Community Health 1992; 46: 409-416

Human Nutrition, PO Box 10041

Gouger Street Adelaide SA 5000,

Australia

A M Smith

K I Baghurst

Correspondence to: Ms Smith

Studies undertaken in developed countries show that social status has an influence on all cause mortality, ${ }^{12}$ in particular mortality from certain cancers, coronary heart disease and stroke, respiratory diseases, digestive diseases, and motor all, higher disease rates are seen in those of lower social status. These differences may be the result of the varying lifestyles of the social groups including factors such as diet, exercise, and alcohol and cigarette consumption. Alternatively, they may be more closely related to socioeconomic and environmental causes such as variation in exposure to environmental hazards at home or at work, or to other direct effects of social inequality including ability to gain access to financial and educational resources. ${ }^{2}$

In Australia, mortality from lung cancer in men and stroke in both men and women has been shown to be increased in lower social status groups. However, three major diet and lifestyle related diseases, namely colon and breast cancer, and diabetes mellitus, have not shown social ciass trends. ${ }^{45}$ The strongest social class trends in Australia relate to coronary heart disease where cross sectional data show higher age adjusted death rates in lower status occupations of between $20 \%$ for men and $50 \%$ for women. ${ }^{45}$ Longitudinal data have also shown that the major reduction in coronary heart disease that has occurred in Australia, the USA, and the United Kingdom over the past two decades has occurred to a much greater extent in those of high social status. ${ }^{367}$

Despite these differences in mortality trends, which are reflected in many other countries, the underlying prevalence rates of smoking, levels of exercise, and intakes of alcohol and dietary components in different social status groups have been sparsely documented. Cigarette smoking in the United Kingdom ${ }^{8}$ and cigarette smoking and overweight in the USA ${ }^{9}$ have been shown to be less prevalent in higher status groups. There is some evidence of healthier eating habits in upper status groups in the USA ${ }^{1011}$ but not in the UK. ${ }^{812}$ In Australia, evidence of increased activity patterns ${ }^{6}$ and lower rates of smoking ${ }^{6}{ }^{13}$ in professionals compared with all other occupations has been demonstrated, and there is limited evidence of less healthy eating habits in those of lower occupational prestige, ${ }^{14-19}$ although these analyses were not controlled for confounding by age. Despite this paucity of evidence, specific targeting of nutrition programmes to those of lower social status has been proposed in a series of Australian government policy reports aimed at providing a framework for improving the health of the nation and improving equity across various sectors of the community. ${ }^{142021}$

The aim of this study was to establish whether vehicle accidents. ${ }^{3-5}$ In most cases, although not groups in Australia with respect to food choice and nutrient intake and, if so, whether they were of a kind likely to influence health outcome differentially across social groups. We wished to 
discover the social status measure of choice, and to provide comparative data to aid interpretation of studies which have used only one measure.

\section{Methods}

SURVEY METHODOLOGY AND ADMINISTRATION

A sample of 1500 adults was randomly selected from the Australian electoral rolls for Adelaide, Perth, and Brisbane. As voting and registering to vote is compulsory for all Australian citizens, the electoral rolls contain the names of over $98 \%$ of all those over the age of 18 years. The cities chosen for this study are the capital cities of three of the Australian states. They are of similar size (around one million people) and of broadly similar demography, in terms of income, education, ethnicity, and age, although Adelaide has a slightly older population, and Perth a slightly younger one. ${ }^{22}$ Data for all cause mortality and mortality due to major chronic diseases (neoplasms and coronary heart disease) were very similar, after the effects of differences in age profiles had been accounted for. ${ }^{23}$ No major differences between cities in food or nutrient intakes was expected based on previous surveys. ${ }^{2425}$

Given an expected shortfall of 500 due to population mobility, mortality, and inability or refusal to take part, a sample size of 1500 was selected to yield a power of $0.85-0.95$ to distinguish differences of $5-10 \%$ in variable values between major population subgroups. The survey was administered by mail using the method described by Dillman. ${ }^{26}$ It was initially posted out to the sample population in May 1989 with a preaddressed, prepaid reply envelope. A covering letter was enclosed explaining the purpose of the study. This letter also assured strict confidentiality of information received. After two weeks, a reminder postcard was sent to all nonrespondents encouraging them to reply and assuring them of confidentiality once again. After four weeks a replacement questionnaire, cover letter, and return envelope was posted to nonrespondents. After eight weeks, the remaining non-respondents were followed up by telephone if their number was available in the telephone directory, or by certified mail.

\section{THE SURVEY INSTRUMENT}

The survey instrument was a booklet containing questions relating to usual food intake over the previous year or so and questions about social and economic background. Information regarding respondents' and their spouses' occupational and educational status was also obtained, as well as their household income category. If respondents were retired, their usual occupation before retirement was assessed. These measures were later used to categorise respondents into social groupings as discussed later. Usual food intake was assessed using a quantified food frequency questionnaire format including a list of 172 food and drink items with specified sizes of servings and supplemented with questions about specific types of food eaten, and cooking and preparation methods, which were used to modify the nutrient analysis. Questionnaires using this format have been used extensively in Australian statewide and nationwide dietary surveys. ${ }^{17} 1827$
The food item list was marked off by respondents as shown using an open ended scale according to whether they considered they usually ate a food, never " $N$ ", rarely " $R$ ", or a number (n) times a month "nM", a week "nW", or a day " $\mathrm{nD}$ ". For example, someone eating four slices of bread a day would respond 4D next to "Bread, 1 slice". A comment column was available to alter sizes of servings where appropriate and special attention was given to seasonal foods. Qualitative and quantitative information was also gathered and used to adjust data from the main frequency grid as follows: specific food types which could have one of several different nutrient compositions (eg, breads, cereals, fat spreads); frequency of use and relative amount of discretionary sugar and salt; use of low salt or fat alternative; and food preparation habits, such as trimming the fat from meat and cooking methods used. Additional open ended questions on intake of foods not included in the frequency list completed the food frequency questionnaire.

Average daily nutrient intake data were derived using the Frequan program. ${ }^{27}$ The computer program calculates average daily nutrient intake from the frequency questions after adjusting the data according to the qualitative and quantitative answers described above. Meat serves are trimmed of fat as appropriate by adjusting the fat content downward, and the type of cooking fat nominated is used in nutrient computation. Relevant nutrient composition data are used for type of dairy foods, low salt foods, and energy reduced foods nominated. Milk and sugar is totalled for that added to cereals and hot beverages. The nutrient database used the revised British tables, ${ }^{28}$ with modifications for Australian data where necessary.

As energy needs inevitably vary across some of the socioeconomic groups of interest (eg, men versus women; manual versus non-manual workers; and by age), comparisons of dietary quality (intake of nutrient or food/unit energy intake) rather than absolute quantity ( $\mathrm{g}$ or $\mathrm{mg}$ per day) were used to compare groups. To assess nutrient quality of the diet two different approaches were used. For nutrients contributing to total energy intake, percent energy contributed by that nutrient was used (including percent energy from fats, protein, carbohydrates and alcohol), while other nutrients were expressed as daily intake per $10 \mathrm{MJ}$ of energy intake (including salt, fibre, and cholesterol). For analytical purposes, it was necessary to use the natural logarithms of food and nutrient density for all nutrients except percent energy from fat and sodium density and most food groups, in order to normalise the distributions statistically. Mean nutrient densities were therefore represented by geometric means and not arithmetical means.

\section{SOCIAL CLASS GROUPS}

Four measures which provide information on social and economic advantage were used, two relating to occupation and one each relating to income and education. Data on past (if retired) or present occupation and spouse's past or present occupation (if applicable) were coded using two scoring methods. A scale of occupational prestige was used to code occupational status using a two 
digit continuous scale ranging from 10 to $70 .^{29}$ The continuous scale was used in determining the significance of social trends in nutrient and food intake. This scale was also used to form a categorical variable of five equally sized groups, ie, quintiles, for tabulating nutrient intake data or for assessing the numbers of people lying outside recommended intakes. This scale was developed specifically for the Australian population and is derived from survey data collected from selected occupational sample groups relating to lay perceptions of the relative prestige of certain occupations.

A second rating was given for occupational category which groups occupations according to training and qualifications needed for the job. ${ }^{30}$ The one digit classification system was used, ranging from 1 to 8 (eg, $1=$ managers; $2=$ professionals; 3 =paraprofessionals; $4=$ tradespersons; $5=$ clerical workers; $6=$ salespeople; $7=$ semiskilled manual workers; $8=$ unskilled manual workers). Retired persons were coded by their past occupation, and students by their future occupation if one was possible to predict. All respondents who were married (or in a de facto relationship) and were not in employment at the time of the survey were coded according to their spouse's or partner's occupation, unless they had nominated a past occupation which had a higher prestige than that of their partner.

The third measure of social position was based on education. Years of schooling and highest qualification received since leaving school were used to construct a four point educational status score. The first group included those who had left school at 16 years of age or younger, the second included those who left at 17 years of age or older and were without further education, the third included the holders of technical and trade certificates, and the fourth was the holders of diplomas, degrees, and higher degrees. Educational status related solely to the respondent's training and was never substituted by spouse's training.

The final measure of social position used was household income level. Respondents were asked to nominate one of six categories of gross household income. Categories used accorded with classifications used for the Australian census with adjustment for inflation between the time of the census and the time of the survey. The fourth income level would have represented the median at this time, while the lower income levels represented old age pension and unemployment benefit levels. Household income code was then adjusted to some degree for number of persons in the household so that some comparison could be made between individuals in households with different numbers of occupants. This was somewhat arbitrarily accomplished by adjusting the code down by 1 if the household included more than one adult or child.

STATISTICAL ANALYSIS

Multiple linear regression analysis was used to test for linear relationships between nutrients and social status measures. Analysis of variance was performed to test for non-linear associations of mean nutrient intakes among occupational categories. Both were adjusted for age and sex related differences between groups. $\chi^{2}$ Tests were per- formed on proportions in occupational prestige quintiles. The research described in this paper was approved by the ethics committee of the CSIRO Division of Human Nutrition.

\section{Results}

\section{REPRESENTATIVENESS OF THE SAMPLE}

The response rate after the three initial mailings and six weeks was $56 \%$. The response rate rose to the final $70 \%$ over the next couple of months due to late responders, and also due to an increasing the number of returns in response to follow up of non-responders by telephone and certified mail. Part of the increased response rate was also caused by the identification of more non-contacts (due to death, moving house to unknown addresses, or movement interstate or overseas), who were then eliminated from the denominator. There was a total of 259 non-participants who were disregarded in this way. A final response rate of $70.4 \%$ was achieved, representing 874 participants of the 1500 minus 259 people who were contacted. Response rates differed only slightly between cities $(68.4 \%$ in Adelaide, $74.4 \%$ in Perth, and $69.3 \%$ in Brisbane).

The survey sample was compared by age, gender, country of birth, occupation, education, and income distributions to the Australian population as a whole using data from the 1986 census, in order to assess any undue bias in the respondent population caused by the survey methodology. The main biases in the sample were: the overrepresentation of people with postsecondary education (observed proportion was $50 \%$, expected $33 \%$ ); the underrepresentation of manual workers (observed $16 \%$, expected $23 \%$ ) and overrepresentation of professionals and paraprofessionals (observed $28 \%$, expected $20 \%$ ); the underrepresentation of 18-29 year olds (observed $22 \%$, expected $28 \%$ ); and females who were not in the labour force (observed $36 \%$, expected $52 \%$ ). In terms of other age, sex, ethnic origin, income, and occupation groups, proportions were within $5 \%$ or less of expected values.

While all social status measures showed some confounding by age and sex, occupational prestige quintiles were less affected than occupational category, level of qualification, or household income level. There were high proportions of females in clerical and sales categories (and these occupational groups tended to be younger also), and males in trades and semiskilled manual occupations. Females and older age groups were particularly highly represented in the group who had left school before 16 years of age, and in the group with the lowest household income. Males were more likely than females to have had trade and technical qualifications.

RELATIONSHIP BETWEEN SOCIAL STATUS MEASURES AND NUTRIENT DENSITY LEVELS

The directions and strengths of the linear associations between nutrient densities and occupational prestige, educational status, and income status, as well as non-linear associations with occupational categories are shown in the four right hand columns of table I. Age and sex were adjusted for in the analyses as necessary, as these 
were confounding factors in several relationships between nutrient intake and social status, as was indicated above. The three methods of status groupings showed similar patterns of association with nutrient density, although the numbers and strengths of relationships varied among social indicators. The occupational prestige variable was correlated most strongly with nutrient densities both in terms of the numbers and the strengths of correlations.

Lower occupational status respondents had higher energy intakes, higher contributions of energy from total, saturated, and monounsaturated fat and refined sugars, and a higher density of cholesterol in the diet. Higher status respondents had a larger contribution of energy from natural sugars and alcohol, and a higher density of fibre in the diet. Contributions of protein, polyunsaturated fat, and complex carbohydrates to energy intake, and salt density did not differ by occupational status.

Educational status showed weaker, but otherwise similar, inverse associations with percent of energy from total, saturated, and monounsaturated fats and refined sugar and a positive association with fibre density. Income level was also similarly inversely related to percent of energy from fat and natural sugar, and income level was positively related to high alcohol intake. Although income level was unrelated to fibre density, high income was positively associated with high percent energy from complex carbohydrate.

Grouping by the training and qualification based occupational categories also showed that there were differences in energy intake, percent energy from alcohol and fibre density. Professionals and paraprofessionals had the highest fibre density in the diet, while the manual labouring occupations consumed the least. For alcohol, managers, professionals, and salespeople had the greatest alcohol consumptions, and unskilled manual workers the least. When energy intake was analysed separately for males and females, a strong relationship was found between occupational category and energy intake for males, but no relationship was found for females. Males in manual labouring occupations had higher energy intakes, in the range between 10260 and $10700 \mathrm{~kJ} / \mathrm{d}$, than those in sedentary occupations whose intakes ranged between 8640 and $9850 \mathrm{~kJ} / \mathrm{d}$ $(F=2.99 ; \mathrm{df}=7,375 ; \mathrm{p}<0.01)$.
All four methods of social grouping showed nutritional associations in similar directions, with occupational prestige having the strongest and largest number of associations. It was therefore decided to use occupational status as the method of comparison in the following nutrient analyses.

The nutritional, as opposed to statistical, significance of these findings is indicated by the mean nutrient density levels of the occupational status quintiles shown in the middle columns of table I. The largest social status differences were seen for fibre, natural sugar, and refined sugar densities $(17 \%, 16 \%$, and $15 \%$ differences between lowest and highest groups respectively). High status groups had larger intakes of fibre and naturally derived sugars and lower intakes of refined sugars. Differences in saturated and monounsaturated fats represented much smaller increases of only $8 \%$ from the high-mid (2nd) to the lowest (5th) occupational prestige quintile, while total fat increased by only $6 \%$ across these same groups. In all cases the uppermost (1st) quintile had slightly higher fat intakes than the upper-middle and the middle quintiles, thereby reducing the strength of the linear trend. Thus, although differences across groups were statistically significant, variations in mean intakes were not large. The variance in nutrient density in the diets of respondents which was accounted for by occupational prestige score was also of a moderate magnitude, ranging from zero for several nutrients to a peak of $3.3 \%$ for natural sugars, as shown in the left hand column of table I.

To assess further the implications of differences between social status groups, the proportions of respondents in occupational prestige quintiles who had dietary intakes within recommended levels were calculated for fat (less than $33 \%$ of energy, ${ }^{21}$ or less than $30 \%$ of energy ${ }^{31}$ ), fibre (at least $30 \mathrm{~g}$ per day), refined sugar (less than $12 \%$ of energy), sodium (between 900 and $2300 \mathrm{mg}$ per day $^{21}$ ), and alcohol (no more than two drinks per day for women or four per day for men, with some alcohol free days ${ }^{32}$ ). The proportion of people from various social groups complying with dietary guidelines was only significantly different in relation to total fat $\left(\chi^{2} 11.53, \mathrm{df}=4, \mathrm{p}<0.025\right.$ for the $30 \%$ fat recommendation; and $\chi^{2} 11.98$, $\mathrm{df}=4, \mathrm{p}<0.025$ for the $33 \%$ fat recommendation), and refined sugar intake $\left(\chi^{2} 12.45\right.$, $\mathrm{df}=4, \mathrm{p}<0.025)$. Almost twice the number of subjects in the upper occupational prestige group
Table I Variation in nutrient intake in occupation, education, and income groups

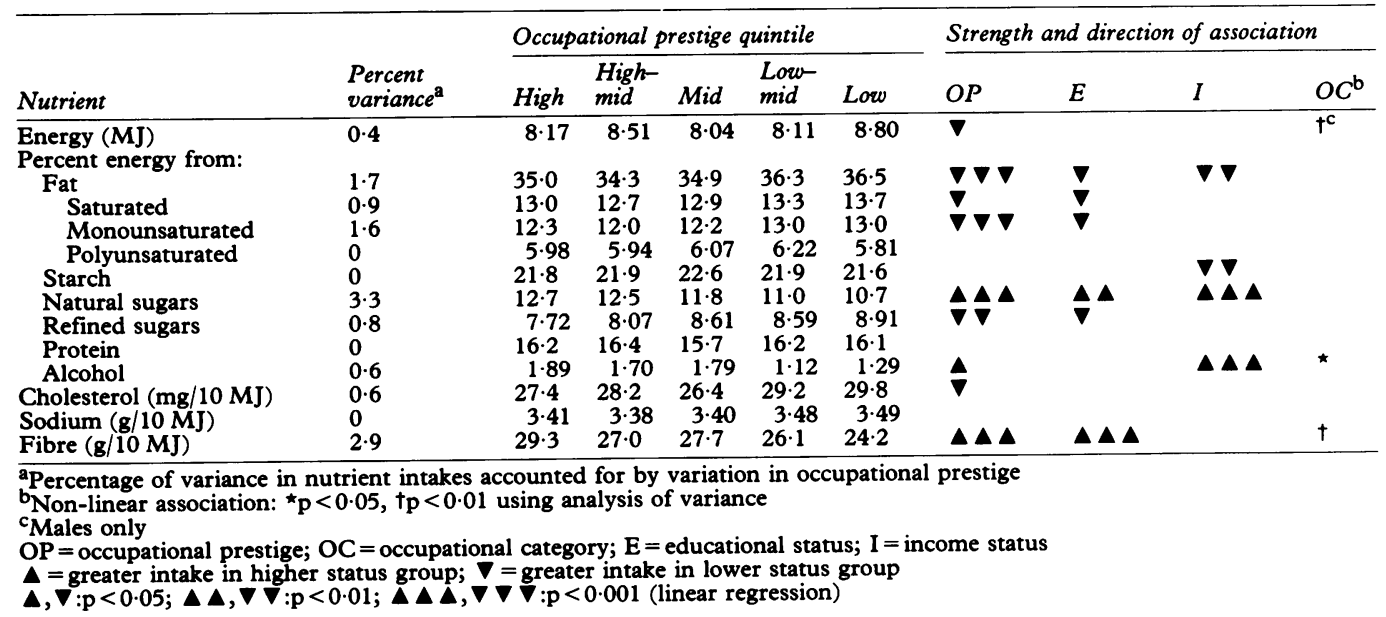


complied with the targets for fat, although this was still only achieved by a small proportion of people (eg, $19 \%$ versus $9 \%$ for the $30 \%$ fat recommendation). There was no significant trend for the other nutrients for which recommendations exist, namely, alcohol, salt, and fibre.

\section{RELATIONSHIP BETWEEN SOCIAL STATUS AND FOOD} CHOICES

As some food related risk factors for conditions such as cancer are not thought to act through nutrients per se, but through some other, as yet unknown, food component (such as the protective factors in cruciferous vegetables) and as knowledge of food patterns can be useful in designing intervention strategies should these be necessary, the pattern of food usage among the various social status groups was also investigated.

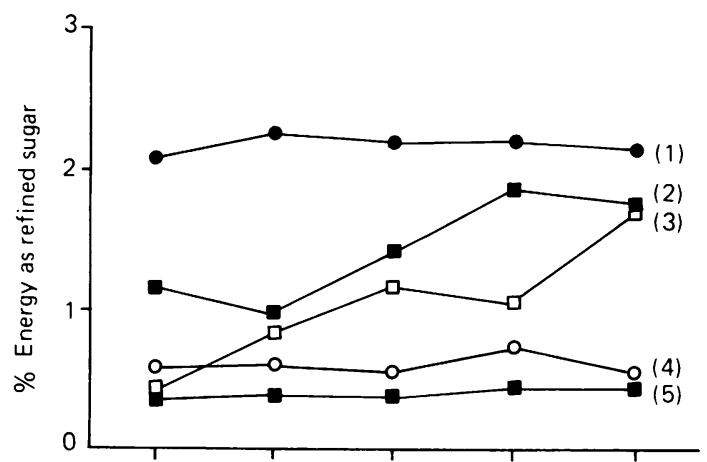

Major food groups contributing to $\%$ energy intake as refined sugar, and to fibre density in occupational prestige quintiles.

(1) = confectionery;

(2) = cordials and soft drinks; (3) = added sugar; (4) = cakes and biscuits; (5) = milk containing desserts and flavoured milk drinks; (6) = all vegetables; (7) = wholegrain breads and cereals; $(8)=$ all fruit; (9) = refined breads and cereals

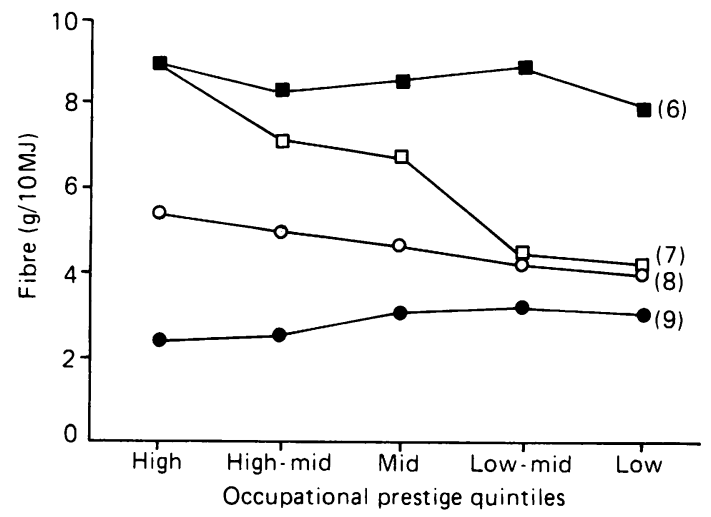

Table II Linear associations between food group intake and social status measures

\begin{tabular}{|c|c|c|c|c|c|c|c|c|c|}
\hline Food group & $O P$ & $O C$ & $E$ & $I$ & Food group & $O P$ & $O C$ & $E$ & $I$ \\
\hline $\begin{array}{l}\text { "High status related" } f \\
\text { Wholegrain breads an } \\
\text { cereals } \\
\text { Rice, pasta } \\
\text { Fruit }^{\mathrm{a}} \\
\text { Fruit, seasonal }^{\mathrm{a}} \\
\text { Low fat milk } \\
\text { Meat dishes } \\
\text { Dried beans (legumes) } \\
\text { Carrots, pumpkin } \\
\text { Salad vegetables } 1^{\mathrm{a}} \\
\text { Salad vegetables } 2^{\mathrm{a}} \\
\text { Fruit juice } \\
\text { Cheese } \\
\text { Alcoholic beverages } \\
\text { Leafy green, brassica } \\
\text { vegetables }\end{array}$ & 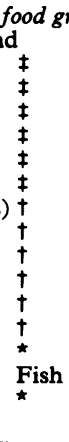 & $\begin{array}{l}+ \\
+ \\
\star \\
\star \\
\vdots \\
\star \\
\star \\
+ \\
\star \\
+\end{array}$ & $\begin{array}{l}\star \\
\ddagger \\
\ddagger \\
\ddagger\end{array}$ & $\begin{array}{l}\ddagger \\
\dagger \\
\star \\
\ddagger\end{array}$ & $\begin{array}{l}\text { "Low status related" fooc } \\
\text { White bread and } \\
\text { refined cereals } \\
\text { Fried meat } \\
\text { Meat products } \\
\text { Discretionary sugar } \\
\text { Full cream milk } \\
\text { Potatoes boiled, mashed } \\
\text { Takeaways, pies } \\
\text { Eggs }\end{array}$ & $\begin{array}{l}\text { oups } \\
\text { Cake } \\
\text { Choc } \\
\text { Lolli } \\
\text { Cord } \\
\text { Poly } \\
\text { ma }\end{array}$ & $\begin{array}{l}\text { es, bis } \\
\text { colate } \\
\text { ies, jan } \\
\text { lial, so } \\
\text { unsatu } \\
\text { argarin }\end{array}$ & $\begin{array}{l}\text { uits } \\
\text { ms } \\
\text { oft drin } \\
\text { urated } \\
\text { ne }\end{array}$ & nk \\
\hline $\begin{array}{l}\text { a“"Salad vegetables 1" } \\
\text { vegetables 2" includes } \\
\text { banana; "seasonal frui } \\
\text { includes cream, ice cre } \\
\text { includes various styles } \\
\text { includes frankfurters, } \\
\text { pies, pasties, sausauge } \\
\text { OP = occupational pres } \\
\text { status } \\
\text { ^p }<0.05 ; \text {; }<0.01 ; \neq p\end{array}$ & $\begin{array}{l}\text { it" inc } \\
\text { eam, c } \\
\text { sof ste } \\
\text { bacon, } \\
\text { rolls, } \\
\text { stige; }\end{array}$ & $\begin{array}{l}\text { sstard } \\
\text { ws, ca } \\
\text { ham, } \\
\text { pizza, }\end{array}$ & & & $\begin{array}{l}\text { hion, mushroom, and be } \\
\text { leslaw; "fruit" includes } \\
\text { stone fruits, grapes; "c } \\
\text { gs, and flavoured milk } \\
\text { heat and pasta dishes; " } \\
\text { t, and salami; "takeawa } \\
\text { tegory; E = educational }\end{array}$ & y des & "salad & $\begin{array}{l}\text { e, and } \\
\text { dishes" } \\
\text { include } \\
\text { some }\end{array}$ & \\
\hline
\end{tabular}

Thirty three groups of nutritionally related foods were formed. To account for variation in total food intake requirements across groups, the amount of food eaten per $10 \mathrm{MJ}$ of energy consumed was used as the comparative unit. Food groups were classified as "high status related", "low status related", and "status unrelated", on the basis of their correlation with occupational prestige measures (table II).

In order to establish the variations in food intake patterns that might be contributing to nutrient intake differences, the median contributions of these food groups to intakes of fat, fibre, cholesterol, and natural and refined sugars were derived. Of the major food groups contributing to dietary fat intake, only two varied between the top and bottom status group: full cream milk (a larger contributor in lower status groups) and cheese (in higher status groups). A larger consumption of eggs was the single main dietary factor contributing to the higher cholesterol density of the diets of the lower occupational prestige groups.

The higher relative intake of refined sugars in the lower status groups was mainly due to a larger contribution from discretionary sugar, as shown in the figure. Cordials, soft drinks, and fruit juice drinks also appeared to contribute more sugar to the diet of lower social status groups, but the difference was not statistically significant. While refined sugars increased as a proportion of energy with decreasing social status, percent energy from naturally derived sugars conversely decreased. Fruits and fruit juices accounted for the majority of the difference in natural sugar density between social groups. High status groups had a very much larger intake of wholegrain cereals, which accounted for most of the difference in fibre intake among groups, also shown in the figure. Higher status groups also received more fibre from fruits.

Analysis of questions concerning dietary habits was performed in order to test for differences in these among occupational prestige groups. The dietary habits that trended upwards with occupational status included: use of low fat milk (used by $38.4 \%$ of the lowest social status group and $56.6 \%$ of the highest social status group; $\chi^{2} 17.07$, $\mathrm{p}<0.01$ ) with a concomitant downward trend in use of full cream milk; wholemeal bread $(36.2 \%$ and $\left.59.1 \% ; \chi^{2} 22.23, \mathrm{p}<0.01\right)$; non-use of sugar in tea $\left(54.8 \%\right.$ and $\left.75.4 \% ; \chi^{2} 16.68, \mathrm{p}<0.05\right)$ and coffee $\left(48.0 \%\right.$ and $\left.64.9 \% ; \chi^{2} 11.23, \mathrm{p}<0.05\right)$; and cooking of certain meats by methods other than frying (beef sausages, $65.5 \%$ and $80.7 \%, \chi^{2} 15.3$, $\mathrm{p}<0.01$; and steak, $66.7 \%$ and $77.8 \%, \chi^{2} 9.49$, $\mathrm{p}=0.05$ respectively). The trends in food habits were generally linear across groups. No significant differences were found in the use of butter versus margarine, eating most or all versus none or little of the fat on meat, or in the use of table salt.

\section{Discussion}

The associations of various measures of social status with nutrient and food intakes have been investigated in population samples from developed countries such as Australia, ${ }^{19}$ the USA ${ }^{11}$ and the UK, ${ }^{812}$ but this is the first study in a large population sample which thoroughly investigated 
social status in relation to both nutrient and food intakes using multiple measures of social status and taking age and gender confounding into account.

Four different measures of social position, namely occupation, occupational status, education, and income, were examined in this study. The aim was to compare the direction and strength of association for each measure of social status with dietary intake. Education and income tap two important but distinct influences on social position which have direct explanatory power. ${ }^{33}$ Occupation would be expected to incorporate both of these factors to some extent, mainly for those in the labour force, and additionally gives information on working conditions, while occupational prestige incorporates other meanings of social position as well.

This could account for occupational prestige having a stronger association with nutrient density levels than educational or income status. While the associations between education and nutrient intake mainly mirrored those of occupational prestige, income levels did provide some additional information, for example low income groups were found to have a larger complex carbohydrate intake, whereas carbohydrate intake did not differ across occupational prestige groups. Nutrient intakes differed little between occupation categories, although energy intakes showed distinct differences between manual and nonmanual categories of males. Occupation seems therefore to have had a lesser influence on dietary quality than social status did, but a marked effect on dietary quantity, at least in males.

In terms of chronic disease risk, the dietary habits of lower social status groups were less in line with nutrient intake recommendations than those of higher social status groups, with the most relevant features being higher total and saturated fat and refined sugar intakes and lower fibre intakes. Intakes of natural sugars and alcohol were consistently higher in upper social status groups, while intakes of monounsaturated fat, cholesterol, and total energy intakes were higher in lower social status groups. However, the differences in nutrient intakes and in the percentages of people attaining recommended intake levels across social groups were narrow compared to the wide gap between the nutrient profile of the whole sample and the recommendations of health authorities. For example, while twice as many people in the upper occupational quintile (compared to those of lower status) attained the recommended level of $30 \%$ energy as fat, $80 \%$ of this group still failed to achieve the target versus $90 \%$ in the lower status group, and for salt intake no difference was found across groups in proportions of people attaining the recommended level. The relatively small differences in dietary profiles between the social groupings examined here do not seem to support the widely held notion, expressed in various government health policy documents, ${ }^{142021}$ that people of lower social standing have a markedly poorer dietary profile compared to those of upper status.

In previous publications on differences in nutrient intake across occupational prestige groups in Australia, ${ }^{19}$ education levels in the USA, ${ }^{11}$ and between manual and non-manual occupations and social classes in the United Kingdom $^{812}$ fibre intake was found to be higher in socially advantaged groups in all three countries, while fat intake was lower in better educated people in the USA and in non-manual Scotswomen, but higher in upper social class Englishmen and women and non-manual Scotsmen. Energy intakes in manual workers in Scotland were also higher than in non-manual workers. ${ }^{12}$ Keys' dietary score, a measure of the atherogenicity of the diet, was found to be lower in better educated men from the USA. Previous Australian studies have described higher natural sugar and alcohol intakes in upper occupational prestige groups, and higher refined sugar intakes in lower occupational prestige groups. The magnitude of the differences seen were between $0 \%$ and $7.5 \%$ for fat intake for all studies, and between $10 \%$ and $20 \%$ for other nutrients. These were similar to the differences which were found in this study between upper and lower status groups of around $5 \%$ for fat intake and $10-17 \%$ for other nutrients.

Although patterns of nutrient intake seen in our study differed less than might have been expected, specific food choices and dietary habits showed some diversity, but also many similarities. Some foods which made large contributions to nutrient intakes, such as grilled and roasted meat, bread, fat spreads, cakes, biscuits, and dairy foods, were eaten in similar amounts by all social groups. Nutrient intake differences were due to type of foods chosen within food categories, such as wholemeal versus white bread or full cream versus low fat milk; to variations in cooking methods used, such as the numbers of respondents preferring frying to grilling; and to specific habits such as the use of discretionary sugar in beverages or on cereals. Overseas and Australian studies have found some quite similar results to those found in this study. Better educated women in the USA ${ }^{11}$ and upper occupational prestige men and women in Australia ${ }^{161719}$ have previously been found to eat more high fibre bread, low fat milk, cheese, and fruits and vegetables, although the better educated North American women also used more full cream milk, high fat high salt snacks, and high fat desserts. Smaller intakes of high fibre foods and fruits and vegetables have also been described in people in the USA with a higher poverty index, ${ }^{34}$ and in Australia in low occupational status groups. ${ }^{19}$ Scottish non-manual workers were also found to eat more fruits and vegetables, while manual workers consumed larger relative amounts of fried meats and meat products, as was found in our study and other studies of Australian populations using occupational prestige (uncontrolled for age bias). Our study and the Scottish study found a more frequent use of discretionary sugar in lower status and manual workers, respectively. The Scottish study found a larger alcohol consumption in manual workers, but we found that upper status groups reported larger alcohol intakes.

In relation to chronic disease aetiology, coronary heart disease is the only condition for which we have some generally accepted estimate of the magnitude of dietary change required to bring about a definable difference in mortality. ${ }^{35} 36$ Our study indicates that differences in nutrient intake 
are unlikely to be of such a magnitude as to be a major cause of the existing cardiovascular disease inequality across social groups, at least in relation to the atherosclerotic process. Predicted atherogenicity of the diets of occupational status quintiles was calculated using the formula of Anderson and colleagues. ${ }^{35}$ The difference in nutrient intake constituted a difference of only $0.85 \%$ of total plasma cholesterol between the top and bottom occupational prestige quintiles. This translates into an estimated coronary heart disease mortality difference of $1.7 \%$ between the top and bottom social status groups. ${ }^{35}$ Lower status groups in Australia have been reported as having $22 \%$ and $50 \%$ excess coronary heart disease mortality in males and females respectively. ${ }^{5}$ The atherosclerotic process is, of course, not the only mechanism whereby diet can influence cardiovascular risk, but it is a major component. The nutrients that can influence this process, notably the amount and type of dietary fats and cholesterol, are also influential in other areas related to cardiac risk such as thrombogenesis and hypertension.

The conclusion that diet may play only a limited role in determining the differential in cardiovascular mortality between social groups is supported by the work of Dobson and colleagues ${ }^{6}$ who found no difference in serum cholesterol level (one of the major markers of dietary risk) between occupational categories in the national heart risk factor survey of Australia in 1980 Differences across social groups did exist in blood pressure, triglycerides, cigarette smoking, body mass, and exercise but only when comparing the professional group to all other occupational categories. Our study also found smoking to be more prevalent in lower status groups (only $67.8 \%$ non-smokers in the lowest social status groups compared with $83.7 \%$ in the highest; $\chi^{2}$ $18.01, \mathrm{p}<0.05)$, but exercise and prevalence of obesity (as assessed by Quetelet's index) did not vary across groups, although there was a nonsignificant trend to higher exercise participation in upper social groups. Thus, as least in the case of coronary heart disease, the main lifestyle factor in this data set that appeared to have the greatest potential to affect risk differentially across social groups was smoking behaviour.

In terms of assessing the applicability of these data to the whole population, the voluntary base of the sample, the requirement for respondents to complete lengthy questionnaires and the effect of potential sampling and response biases have to be considered. While upper status groups were somewhat overrepresented and lower status groups were underrepresented in numerical terms, the range of income, education, and occupational categories as enumerated by the last census were all well represented in the sample. However, the technique used undoubtedly reduces or minimises the participation of certain sectors of the community such as those with limited free time, those with no fixed address or very high mobility, and those disadvantaged by limited literacy or English language skills, disabilities, or homelessness. Further studies using more individualised labour intensive techniques would be required to assess the nutritional profile of these specific disadvantaged groups. There are other potential sources of bias in the comparison across groups in this study including the relevance of questions to various groups and the general language used which could differentially have influenced the outcome. Nevertheless, where relevant data are available from other studies, the general trends seen and the magnitude of the differences do reflect the results from these earlier studies, even though they used a variety of social class indicators and dietary intake methodologies. ${ }^{810}$

In public health terms, generalisation of these results implies that substantial changes in food choices are required across all social groups in the community in order to achieve the community nutrient intake levels targeted by health authorities. Based on the results of this study, specific targeting of lower social status groups to the exclusion of a widespread population approach to nutrition promotion does not seem justifiable although the specific content and style of programmes should, of course, be tailored to the needs of the target group. From our data, the areas that should specifically be included when working with lower status groups include use of low fat dairy foods instead of full fat varieties, use of fat free cooking techniques, reduction of the use of discretionary sugar and soft drinks, and replacement of low fibre breads and cereals by wholegrain varieties.

In conclusion, occupational prestige was found to be the measure of social status which was most strongly associated with food and nutrient intakes, while education and income showed weaker associations in the same directions. Occupational category was not found to be useful as an indicator of social status differences in nutrient intakes. Our survey did show statistically significant differences across social groups in relation to many of the nutrients of interest in chronic disease aetiology and in certain food choices. However, the differences appear to be of limited importance when considering the relatively low degree of compliance of all social groups with dietary guidelines. In terms of chronic disease risk, nutrient intake differences seen did not appear to translate to major differences in atherosclerosis related cardiac risk across social groups. The influence of dietary intake on other cardiac mechanisms, and conditions such as cancer, is largely unknown and in this regard the relevance of the variations in dietary intake patterns to incidence of these conditions remains to be assessed.

The National Health and Medical Research Council Public Health Research and Development Committee provided salary support for Ms Alison Smith. Ms Sally Record's data basing and computing expertise is also gratefully acknowledged.

1 Kitigawa EM, Hauser PM. Differential mortality in the United States: a study in socioeconomic epidemiology. Cambridge, Massachusetts: Harvard University Press,

2 Townsend $\mathrm{P}$, Davidson N. Inequalities in health: the Black report. Harmondsworth: Penguin, 1982.

3 Marmot MG, McDowell ME. Mortality decline and widening social inequalities. Lancet 1986; ii: 274-6.

4 McMichael AJ. Social class (as estimated by occupational prestige) and mortality in Australian males in the $1970 \mathrm{~s}$ Community Health Stud 1985; 9: 220-30.

5 Siskind V, Copeman R, Naiman JM. Socio-economic status and mortality: a Brisbane Area analysis. Community Health Stud 1987; 11: 15-23. 
6 Dobson AJ, Gibberd RW, Leeder SR, O'Connell DL. Occupational differences in ischaemic heart disease mortality and risk factors in Australia. Am $\mathcal{F}$ Epidemiol 1985; 122: 283-90.

7 Wing $S$. Social inequalities in the decline of coronary mortality. Am f Public Health 1988; 78: 1415-6.

8 Morgan M, Heller RF, Swerdlow A. Changes in diet and coronary heart disease mortality among social classes in Great Britain. $\mathcal{f}$ Epidemiol Community Health 1989; 43 : 162-7.

9 Winkleby MA, Fortmann SP, Barrett DC. Social class disparities in risk factors for disease: eight year prevalence
patterns by level of education. Prev Med 1990; 19: 1-12.

patterns by level of education. Prev Med 1990; 19: 1-12.
10 Kushi LH, Folsom AR, Jacobs DR, Luepker RV, Elmer PJ, Kushi LH, Folsom AR, Jacobs DR, Luepker RV, Elmer PJ,
Blackburn H. Educational attainment and nutrient Blackburn $\mathrm{H}$. Educational attainment and nutrient consumption patterns: The $M$.
Diet Assoc 1988; 88: $1230-6$.

11 Popkin BM, Haines PS, Reidy KC. Food consumption trends of US women: patterns and determinants between trends of US women: patterns and determinants be

12 Bolton-Smith C, Smith WCS, Woodward M, Brown CA Tunstall-Pedoe $\mathrm{H}$. Dietary differences between social clas groups in the Scottish Heart Health Study (abstract). Proc Nutr Soc 1990; 49: 62A.

13 Hill D, Gray N. Australian patterns of tobacco smoking and related health beliefs in 1983. Community Health Stud 1984 8: $307-16$.

14 Health Targets and Implementation (Health for all) Committee. Health for all Australians. Canberra: Australian Government Publishing Service, 1988.

15 Baghurst KI, Syrette JA. The influence of gender and socia class on the nutrient contribution of meat and meat products to the diet of a group of urban Australians. $C$ SIRO Food Res $Q$ 1987; 47: 37-44

16 Baghurst KI, Syrette JA. The effect of gender and occupation on the contribution of dairy foods to nutrient intake in an urban Australian population. Food Technol Aust 1988; 40: 178-85.

17 Syrette JA, Baghurst KI, Record SJ. Sociodemographic determinants of the contribution of cereal foods to nutrient intake in the Australian population. Food Australia 1990; 42: $330-8$.

18 Baghurst KI, Crawford D, Worsley A, Syrette JA, Record SJ, Baghurst PA. The Victorian Nutrition Survey: A profile of the energy, macronutrient and sodium intakes of

9 Baghurst KI, Record SJ, Baghurst PA, Syrette JA, Baghurst KI, Record SJ, Baghurst PA, Syrette JA, in Australia of the intake of food and nutrients implicated in cancer aetiology. Med $\mathcal{J}$ Aust 1990; 153: 444-52.
20 South Australian Health Commission. Towards a South . Adelaide: South Australian Health Commission, 1989.

21 Commonwealth Department of Health. Towards better nutrition for Australians. Report of the Nutrition Taskforce of the Better Health Commission. Canberra: Australian Government Publishing Service, 1987.

22 Australian Bureau of Statistics. 1986 Census, small area summary data: classification by statusical division (microfiche). Canberra: ABS, 1986

23 Australian Bureau of Statistics. 1989 Causes of death Australia, cat No 3303.0. Canberra: ABS, 1991.

24 Commonwealth Department of Health. National Dietary Survey of adults: 1983. No 1. Foods consumed. Canberra: Australian Government Publishing Service, 1986.

25 Commonwealth Department of Community Services and Health. National Dietary Survey of adults: 1983. No 3. Nutrient intakes by capital city. Canberra: Australian Gutrient intakes by capital city. 1989.

26 Dillman DA. Mail and telephone surveys. The total design Dilman DA. Mail and telephone surveys. The

27 Baghurst KI, Record SJ. A computerized dietary analysis system for use with diet diaries or food frequency system for use with diet diaries or food frequency

28 Paul AA, Southgate DAT. McCance and Widdowson's The Paul AA, Southgate DAT. McCance and W
composition of foods. London: HMSO, 1978.

29 Daniel A. Power, privilege and prestige: occupations in Australia. Melbourne: Longman Cheshire, 1983.

30 Australian Bureau of Statistics. Australian standard classifications of occupations (first edition). Canberra Australian Government Publishing Service, 1986.

31 National Research Council (US) Committee on Diet an Health. Diet and health: implications for reducing chronic disease risk. Washington DC: National Academy Press, 1989.

32 National Health and Medical Research Council. Is there a safe level of daily consumption of alcohol for men and women Canberra: Australian Government Publishing Service, 1987.

33 Liberatos P, Link BG, Kelsey JL. The measurement of social class in epidemiology. Epidemiol Rev 1988; 10 : 87-121.

34 Patterson BH, Block G. Food choices and the cancer guidelines. Am f Public Health 1988; 78: 282-6.

35 Anderson JT, Jacobs DR, Foster N, et al. Scoring systems for evaluating dietary pattern effect on serum cholesterol. Prev Med 1979; 8: 525-37.

36 Beaglehole R, LaRosa JC, Heiss G, et al. Serum cholesterol, diet, and the decline in coronary heart disease mortality. Prev Med 1979; 8: 538-47. 